\title{
InSAR-based mapping of surface subsidence in Mokpo City, Korea, using JERS-1 and ENVISAT SAR data
}

\author{
Sang-Wan Kim ${ }^{1,2}$, Shimon Wdowinski ${ }^{1}$, Timothy H. Dixon ${ }^{1}$, Falk Amelung ${ }^{1}$, Joong-Sun Won ${ }^{3}$, and Jeong Woo Kim ${ }^{4,2}$ \\ ${ }^{1}$ Division of Marine Geology and Geophysics, University of Miami, Miami, Florida 33149-1098, U.S.A \\ ${ }^{2}$ Department of Geoinformation Engineering, Sejong University 98 Gunja-Dong, Gwangjin-Gu, Seoul 143-747, Korea \\ ${ }^{3}$ Department of Earth System Sciences, Yonsei University, 134 Shinchon-Dong, Seodaemun-Gu, Seoul 120-749, Korea \\ ${ }^{4}$ Department of Geomatics Engineering, University of Calgary, 2500 University Drive NW, Calgary AB T2N1N4, Canada
}

(Received December 19, 2006; Revised January 4, 2008; Accepted January 4, 2008; Online published May 16, 2008)

\begin{abstract}
Mokpo City, located on the southwestern coast of the Korean Peninsula, has been built on one of the largest areas of reclaimed coastal land in Korea. This reclaimed land is currently experiencing significant ground subsidence due to soil consolidation. We have estimated the subsidence rate of Mokpo City $(8 \times 8 \mathrm{~km})$ using the synthetic aperture radar interferometry (InSAR) and InSAR permanent scatterer (PSInSAR) techniques to analyze 26 JERS-1 SAR images acquired between 1992 and 1998 and six ENVISAT ASAR images acquired in 20042005. Mean subsidence velocity, which was clearly related to reclaimed land, was computed from the JERS-1 PSInSAR analysis. The results indicate a continuous and significant subsidence at three sites (Dongmyung, Hadang and Wonsan), where the subsidence velocity has reached more than 5-7 cm/yr in the area of maximum subsidence. The subsidence rate was found to have decreased in Wonsan and Hadang between 1992 and 1998 , while it remained steady or increased in Dongmyung during the same period. The subsidence extended to the period of 2004-2005, and the subsidence rate predicted by the JERS-1 PSInSAR analysis using a linear model was confirmed by the ENVISAT ASAR InSAR results. Our results show that InSAR/PSInSAR-based subsidence maps are useful for the long-term monitoring of soil consolidation and for defining risk zones in coastal reclaimed regions.
\end{abstract}

Key words: SAR, subsidence, reclaimed land, PSInSAR, JERS-1, ENVISAT.

\section{Introduction}

Ground subsidence is a common occurrence in many urban areas and is most commonly caused by mining, excessive groundwater extraction, soil consolidation, and tectonic movement (Galloway et al., 1999; Hu et al., 2004). Civil engineering structures in urbanized areas can be damaged by the subsidence action directly and/or indirectly, with an example of the latter being flooding in coastal areas, as experienced in New Orleans and Venice (Dixon et al., 2006; Teatini et al., 2005). Consequently, information on ground stability is very valuable when carrying out natural or anthropogenic risk assessments in urban areas.

SAR interferometry (InSAR) method has been used successfully to estimate subtle deformations in the Earth's surface caused by earthquakes, volcanic activity, and urban subsidence (Burgmann et al., 2000; Massonnet and Feigl, 1998; Massonnet et al., 1993; Zebker et al., 1994). Compared with leveling and global positioning system (GPS) measurements, which provide information at the specific observation points, InSAR can provide accurate subsidence information over widespread areas with high spatial resolution. InSAR has been found to be very useful for the long-term monitoring of ground subsidence in urban areas

Copyright (c) The Society of Geomagnetism and Earth, Planetary and Space Sciences (SGEPSS); The Seismological Society of Japan; The Volcanological Society of Japan; The Geodetic Society of Japan; The Japanese Society for Planetary Sciences; TERRAPUB
(Amelung et al., 1999; Fruneau and Sarti, 2000; Strozzi et al., 2003). The permanent scatterer SAR interferometry (PSInSAR) technique is a more recent technological development and has been applied to monitor slow and consistent ground subsidence (Ferretti et al., 2000, 2001; Hilley, 2004). PSInSAR has the advantages of having fewer limitations in terms of the baseline and temporal decorrelation. As a result PSInSAR enables a reliable correction for atmospheric effects and easy analysis of time series of deformation. Since a large number of permanent scatterers are distributed in urban areas, PSInSAR is a very powerful tool for studying urban subsidence. New land reclamation projects are often carried out in areas of tidal flats, shallow seas, or wetlands. The reclamation processes involved, such as soil drying in wetlands or soil loading over tidal flats or on the sea floor, both the unconsolidated sediments as well as the loaded soil to compact. Consequently, continuous subsidence occurs in the reclaimed land. It has been shown that L-band DInSAR is an effective tool in detecting two-dimensional subsidence in reclaimed areas during their construction (Kim et al., 2005b). Although PSInSAR is considered to be more effective for measuring subsidence in urban areas than DInSAR, L-band PSInSAR has not been well tested in coastal cities built on reclaimed land.

Here we present maps of land subsidence obtained by PSInSAR and DInSAR of the reclaimed coastal land on which Mokpo City, Korea, is built. The study area has experienced subsidence due to soil consolidation, however, no 

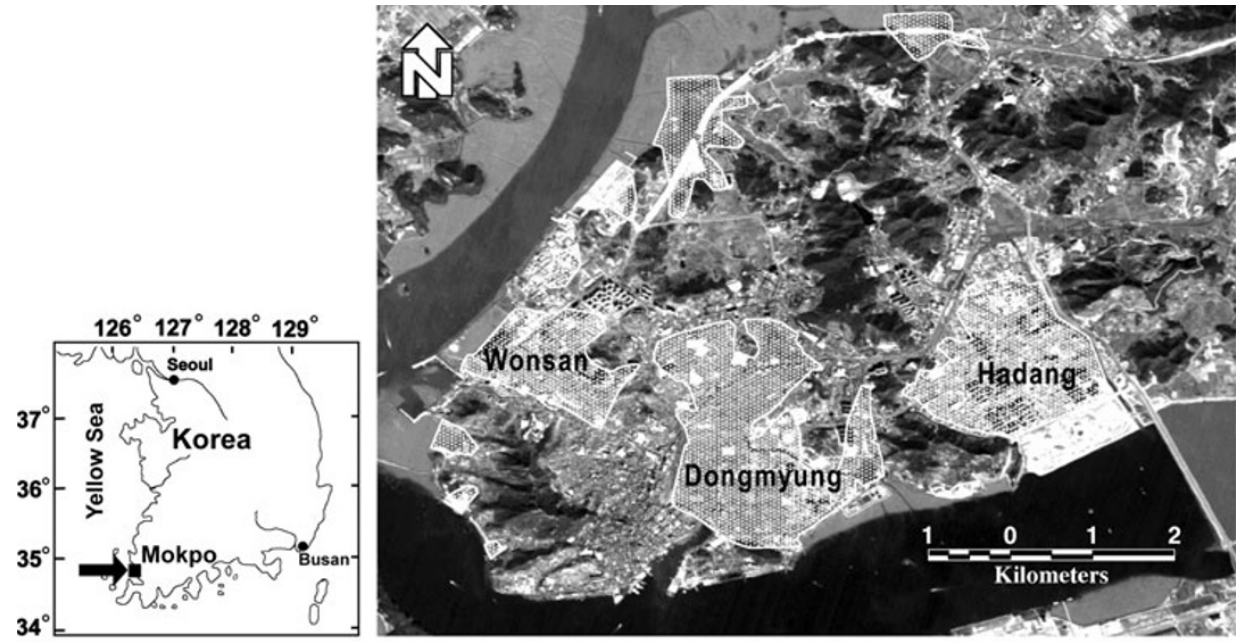

Fig. 1. Location map and IRS-1C optic image of the study area, which is occupied by a coastal city. Dotted polygons represent land reclaimed from tidal flats or areas of shallow sea water since the 1920s. Wonsan, Dongmyung and Hadang are the largest reclaimed blocks in the investigated area.

quantitative ground survey has ever been carried out. The only InSAR study carried out to date used a JERS-1 SAR dataset for the period 1992-1998, which revealed ground deformation in the area of the city in this time interval (Kim et al., 2005a). Here, we extend the time span of the deformation analysis using the combination of JERS and ENVISAT data together with a linear model. The average rate of subsidence was estimated by means of permanent scatterer analysis of 26 JERS-1 SAR data acquisitions during the period 1992-1998, which showed detailed subsidence patterns. The prediction of subsidence in subsequent years was based on a linear model. We used six ENVISAT ASAR data sets acquired during the period 2004-2005 to explore the continuity of subsidence and to verify the subsidence rate predicted from the JERS-1 PSInSAR analyses. Based on these observations, we derived the temporal behavior of the deformation during the last 15 years.

\section{Description of the Study Area}

A number of coastal cities and industrial complexes have been built on reclaimed areas in Korea due to the rapid increase in population. Mokpo City is built upon one of the largest areas of reclaimed coastal land in Korea. Located on the southwestern coast of the Korean Peninsula (Fig. 1), the reclaimed land extends over an area of $47 \mathrm{~km}^{2}$ with a total urban population of 0.25 million. Most of the city area $(\sim 70 \%)$ has been built upon land that has been reclaimed from tidal flats and areas of shallow sea water since the early 1920s. Construction work to build new coastal land is still in progress. In order to detect subsidence in this reclaimed area, we studied an $8 \times 8-\mathrm{km}^{2}$ area that comprises the entire city and the main reclaimed areas (Fig. 1). The main part of the reclaimed land has been used as a major residential district and is densely populated. Three major reclaimed blocks, Wonsan, Dongmyung, and Hadang (Fig. 1), are located at the western, southern, and eastern parts of the investigated area, respectively.

Reclamation was mostly carried out over unconsolidated tidal flat sediments of sand, clay, or silt. The increased loadings during the reclamation caused both the highly com- pressible soil in the underlying tidal flat sediments and the loaded soil to settle. As a result, large regions within Mokpo have experienced significant subsidence. It has been reported for many years that several places in the city have suffered significant damage due to the rapid subsidence; nevertheless, to date, no reliable quantitative measurements are available. Land subsidence can result in severe damage to buildings and road. It is therefore critically necessary to acquire precise measurements of land subsidence in Mokpo City to prevent serious consequences that may be induced by the compaction of soft foundations.

\section{Data Set and Processing}

Multi-temporal radar images are needed for using InSAR and PSInSAR techniques to detect surface deformation. For the study area, we obtained 26 JERS-1 SAR data sets (path: 88, row: 242) from September 1992 to October 1998 and six ENVISAT ASAR data sets (track: 2375, frame: 2907) from August 2004 to September 2005. Figure 2 shows the acquisition dates of JERS-1 SAR and ENVISAT ASAR data and the relative perpendicular baselines with respect to the first data acquisition in each series. We used the PSInSAR technique for JERS-1 data and two-pass differential SAR interferometry for both the JERS-1 and ENVISAT data.

A SAR interferogram, which is a phase-difference image between two single-look complex SAR data sets, consists of several phase components, including the topographic phase, atmospheric phase, and deformation phase. The topographic phase can be removed from the interferogram using a digital elevation model (DEM). We attempted to construct a DEM with a 10-m spatial spacing from the national digital contour maps at the 1:25,000 scale. However, it turned out that the quality of the DEM was not good. The error around the main part of the city extended about several tens of meters because there is no contour over the city area in digital maps. The SRTM-3 DEM with a resolution of approximately $90 \times 90 \mathrm{~m}$ has recently been released to the public, and its accuracy is about $6 \mathrm{~m}(1 \sigma)$ (Muller and Backes, 2003). Therefore, we used a SRTM DEM to re- 


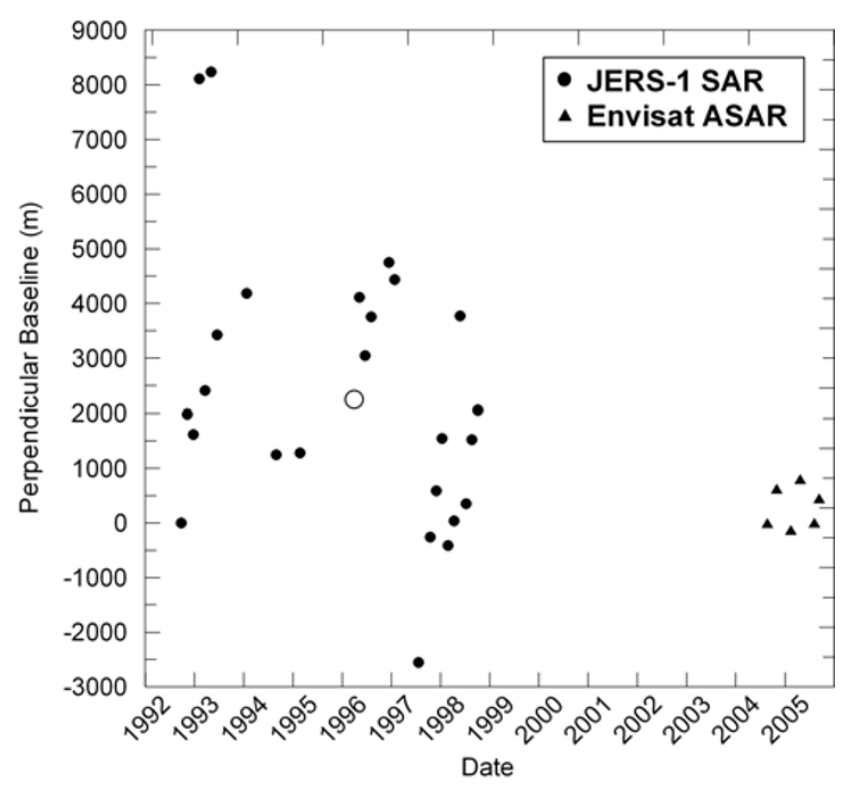

Fig. 2. JERS-1 SAR and ENVISAT ASAR image sets of Mokpo City. The dots and a circle represent the JERS-1 images, and the triangles denote the ENVISAT images with their acquisition dates and relative perpendicular baselines with respect to the first data of each satellite. A circle represents the selected master data in the PSInSAR analysis of the JERS-1 data.

move the topographic effects on the interferograms.

Sixty-three interferometric pairs with a perpendicular baseline of less than $1 \mathrm{~km}$ were selected from the JERS1 SAR series and processed with SRTM 3-arc DEM for the InSAR analysis, with the aim of detecting the amount of subsidence and delineating the subsiding area. The JERS-1 satellite provides inaccurate orbit information; as a result, a residual linear phase frequently remains in the differential interferogram. However, if we assume a short-wavelength deformation in a limited local area, we can consider a loworder phase to be the orbital contribution. Prior to constructing the InSAR-derived subsidence map, we applied a baseline optimization by adjusting a slave (second SAR data in a pair) orbit in order to eliminate low-order residual phase in a topographically corrected interferogram (Massonnet and Feigl, 1998). We carried out a PSInSAR analysis to focus on a subset of image pixels corresponding to point-wise stable reflectors. For the PSInSAR analysis, we constructed 25 JERS-1 SAR interferograms from images acquired on 24 March 1996. We were unable to refine the baselines in three pairs of these interferograms as these had large perpendicular baselines $(>3.5 \mathrm{~km})$ that resulted from a residual phase in the relevant interferogram not being visible due to a severe spatial decorrelation. Therefore, we were able to use only 22 interferograms for the PSInSAR analysis.

Detailed descriptions of the PSInSAR algorithm are provided by Colesanti et al. (2003) and Ferretti et al. (2001). We only briefly summarize the PSInSAR algorithm here. The phase of topographically corrected interferogram at location $(x)$ and each time $(i)$ can be described by:

$$
\begin{aligned}
\phi_{x, i}= & \phi_{\mathrm{defo}, x, i}+\phi_{\mathrm{topo}, x, i}+\phi_{\mathrm{const}, x, i}+\phi_{\mathrm{slope}, x, i} \\
& +\phi_{\mathrm{atm}, x, i}+\phi_{\mathrm{noise}, x, i},
\end{aligned}
$$

where $\phi_{\text {constant }}, \phi_{\text {slope }}$, and $\phi_{\text {atm }}$ (the sum of the three components is called APS (atmospheric phase screen)) are constant phase values, linear phase contributions induced by atmospheric effects and/or orbital fringes, and nonlinear atmospheric effects, respectively (Ferretti et al., 2001). The $\phi_{\text {noise }}$ may comprise the temporal decorrelation, spatial decorrelation, and thermal noise. The $\phi_{\text {defo }}$ and $\phi_{\text {topo }}$ are phase contributions from ground deformation and DEM error $(\varepsilon)$ at each ground target, respectively. A residual phase due to DEM error $(\varepsilon)$ used to subtract topographic phase is expressed by

$$
\phi_{\text {topo }}=\frac{4 \pi}{\lambda} \frac{B_{\perp} \varepsilon}{r \sin \theta}
$$

where $B_{\perp}$ is the orbital separation perpendicular to the satellite flight direction, $\lambda$ is the sensor wavelength, $r$ is the distance between satellite and ground target, and $\theta$ is the look angle. Note that $\phi_{\text {topo }}$ mainly depends on the perpendicular baseline $B_{\perp}$ of the interferometric pair. As a model for ground deformation, a constant velocity model is used here:

$$
\phi_{\text {defo }}=\frac{4 \pi}{\lambda} v \cdot t
$$

The $\phi_{\text {defo }}$ depends on the velocity of deformation $v$ and time separation of interferometric pair $t$. From selected potential permanent scatterers (PSs) based on amplitude stability or coherence stability, the APS is estimated by means of exploiting time series of the phase value. The estimated APS is interpolated spatially, then subtracted from each differential interferogram. After removing the APS, ground deformation and DEM errors can be computed on a pixel-bypixel basis in a multi-interferogram framework because the erroneous phase caused by the DEM error is proportional only to the perpendicular component of the baseline, and surface displacement could be a function of time as Eqs. (2) and (3) independently show.

Two unknown parameters, deformation rate $(v)$ in $\phi_{\text {defo }}$ and DEM error $(\varepsilon)$ in $\phi_{\text {topo }}$, were solved by maximizing the following equation in two-dimensional model space:

$$
\begin{aligned}
\Gamma(v, \varepsilon) & =\left|\frac{1}{n} \sum_{i=1}^{n} e^{j \cdot\left(\phi_{x, i}^{\prime}-\phi_{\mathrm{defo}, x, i}-\phi_{\mathrm{top}, x, i}\right)}\right|, \\
n & =\text { the number of pairs, }
\end{aligned}
$$

where $\phi_{x, i}^{\prime}$ is a phase in the differential interferogram after removing the APS, and $\Gamma$ is the phase coherence. Interferometric coherence ranges from 0 to 1 , which can be considered to be a reliability measure in fitting a deformation model.

The advantages and disadvantages to PS analysis using L-band can be found in (Daito et al., 2003). The precision of the displacement measurement basically depends on the radar wavelength so that the $\mathrm{C}$-band is more preferable. Moreover, JERS-1 can be even worse because of a low signal-to-noise ratio due to a power loss of the transmitted signal. L-band, however, is the more robust approach for detecting a high displacement gradient and atmospheric phase screen attributed to less spatial variation in terms of 

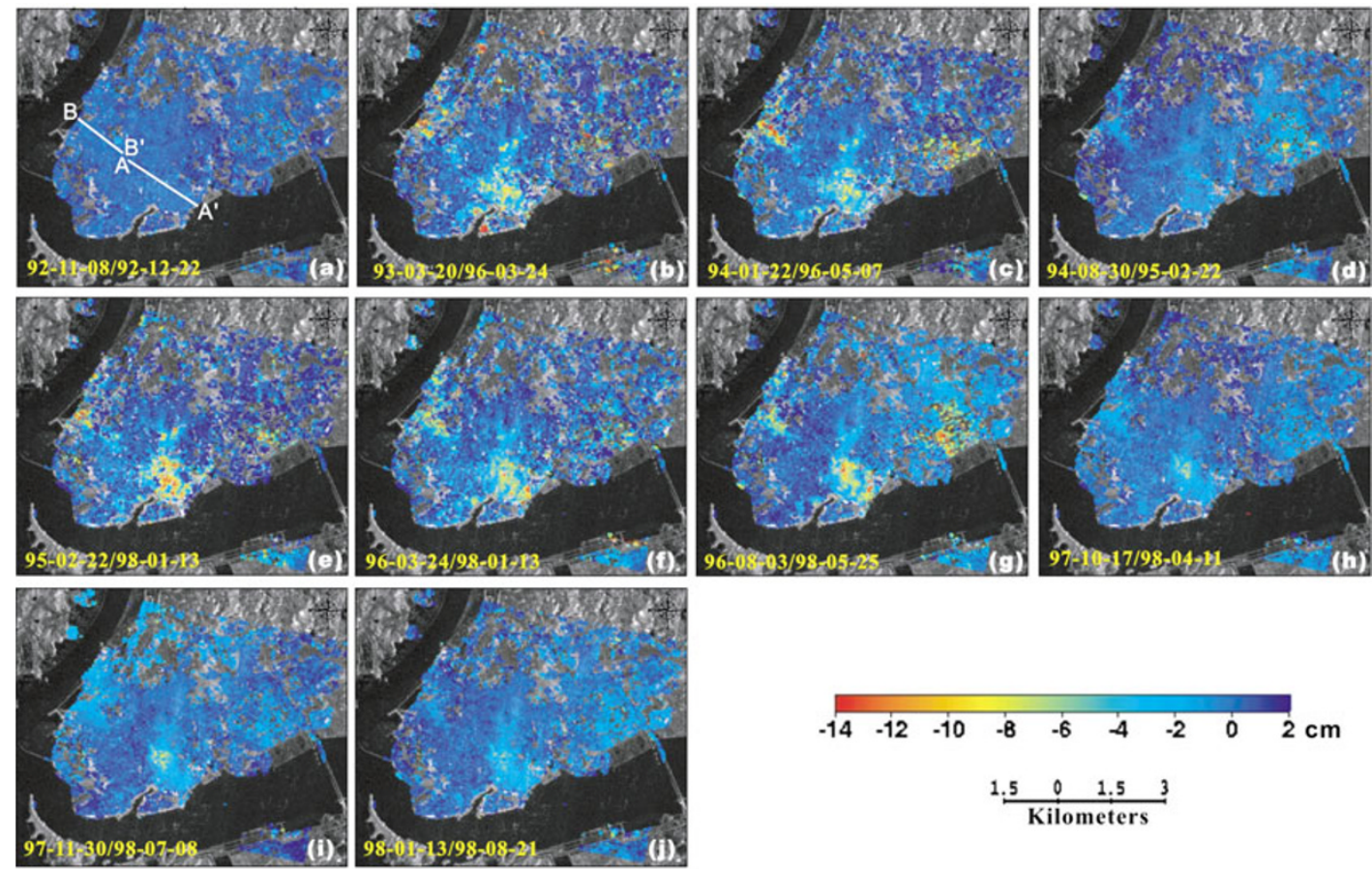

Fig. 3. Subsidence maps derived from the JERS-1 SAR dataset. The color scale represents vertical displacement of the surface. Red denotes rapidly subsiding areas, and blue denotes stable areas. The background image is the multi-image reflectivity map generated from the mean of $26 \mathrm{SAR}$ images. Areas of low coherence are uncolored. Profiles along the line $\mathrm{A}-\mathrm{A}^{\prime}$ and $\mathrm{B}-\mathrm{B}^{\prime}$ are displayed in Fig. 4.

phase values. High coherence and fewer fringes in an interferogram would help to mitigate phase unwrapping error even at PSs with a high-quality signal as well. Moreover, more PS can be detected in the L-band image due to less temporal decorrelation.

\section{Results}

\subsection{Subsidence field from JERS-1 DInSAR measure- ments}

After we had phase unwrapped the DInSAR interferogram using snaphu algorithm (Chen and Zebker, 2001), we converted the phase value into vertical displacement on the assumption of pure vertical movements. This is a reasonable assumption because movements related to soil consolidation are essentially subsidence. A phase cycle $(2 \pi$ in phase difference) corresponds to a vertical displacement of $14.8 \mathrm{~cm}$, given the wavelength of the JERS-1 satellite $(23.5 \mathrm{~cm})$ and the incidence angles $\left(37.3^{\circ}\right)$ at the center of the study area.

Figure 3 shows some examples of highly coherent subsidence maps selected from 63 JERS-1 DInSAR interferograms; these give an insight into the evolution and the amount of the subsidence. The uncolored areas in Fig. 3 represent pixels of low coherence which were masked out in the step of phase unwrapping. Each map represents the subsidence pattern during a given period. Subsidence is significantly observable in all of the maps shown except for the one from the pair of 1992-11-8/1992-12-22 because the 44-day time interval was short. These observations imply that the subsidence in the study area is not short-lived and that it continued at least during the time span of the JERS-1 SAR SAR observations (1992-1998). The southern side of city around Dongmyung was revealed to have experienced the most obvious subsidence. Rapid subsidence was also observed in the Wonsan area during the early time period (1993-1996; Figs. 3(b) and (c)). Although the displacement in the eastern area (Hadang) is a bit obscure, this area can be clearly seen to have also suffered ground displacements.

The profiles shown in Fig. 4 are the subsidence values in some typical interferograms along the line $\mathrm{A}-\mathrm{A}^{\prime}$ in Dongmyung and the line B- $\mathrm{B}^{\prime}$ in Wonsan (Fig. 3(a)). We divided these profiles into three zones (A1, A2, A3) according to the characteristics of subsidence in Fig. 4(a). Zone 'A1' seems to be stable during SAR observations, and the fluctuations of the measurement in this zone are within $\pm 1 \mathrm{~cm}$, which may reflect phase errors due to temporal and geometric decorrelation, or thermal noise. The ground in zones 'A2' and 'A3' had subsided on the order of several centimeters per year. The amounts of subsidence observed in two 220-day pairs between the images acquired after the end of 1997 are comparable to the subsidence estimated from the longer interval pairs of 96-3-24/98-1-13 and 96-8-3/98-5-25, suggesting that the subsidence velocity has increased since September 1997 . In contrast, the measurements in zone 'A3' are generally proportional to the time spans between two acquisitions, suggesting a predominantly uniform subsidence rate. The following two zones were identified along the line B-B' (Fig. 4(b)): a stable zone ' $\mathrm{B} 1$ ', and subsiding zone 'B2'. The subsidence rate in zone 'B2' slowly decreased toward the end of the period 19971998. Figures 4(c) and 4(d) shows the mean PS velocity along the two profiles estimated by the PSInSAR analysis (see following section). The mean PS velocity shows not only a good correlation with the DInSAR profiles but also a clear spatial trend of subsidence that is in contrast to the noisy profiles of the long-term interferogram. 

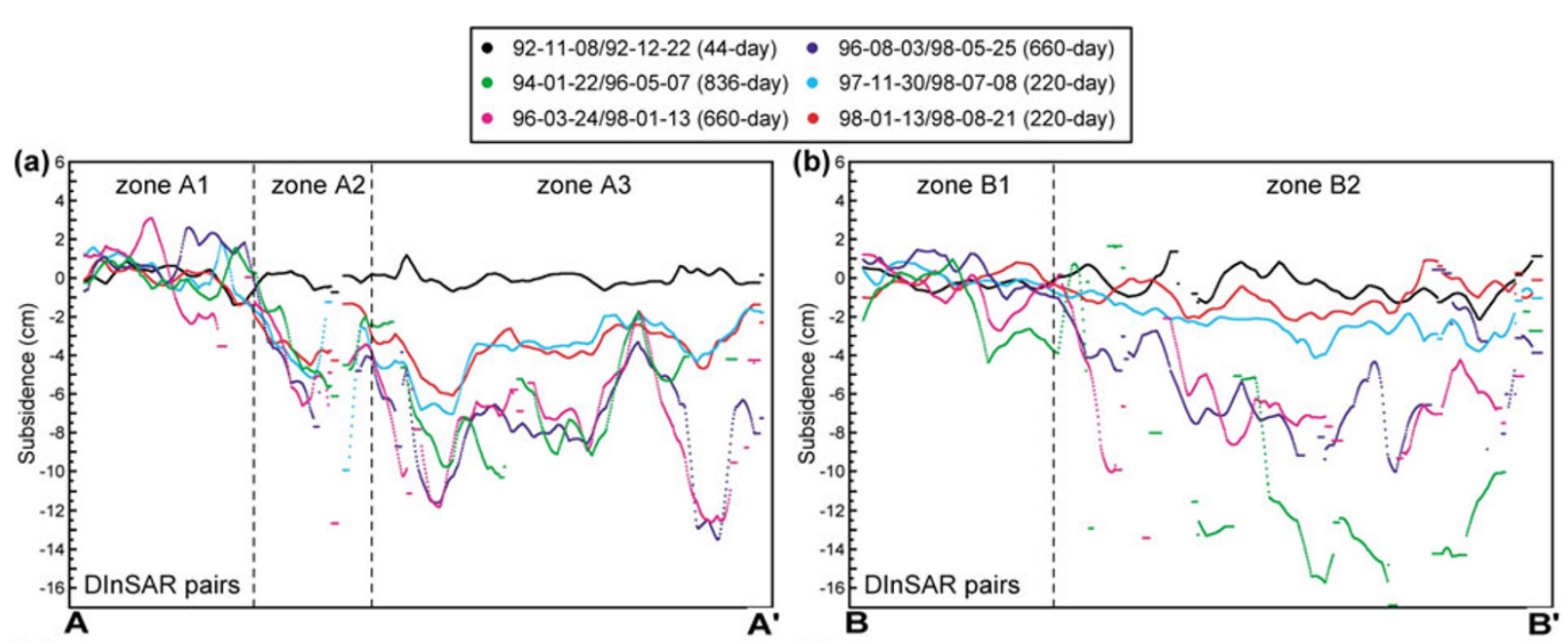

(c)

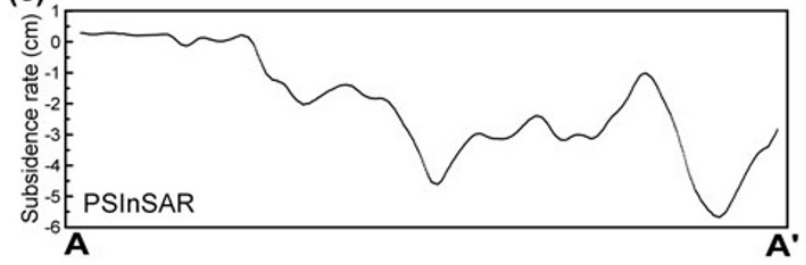

(d)

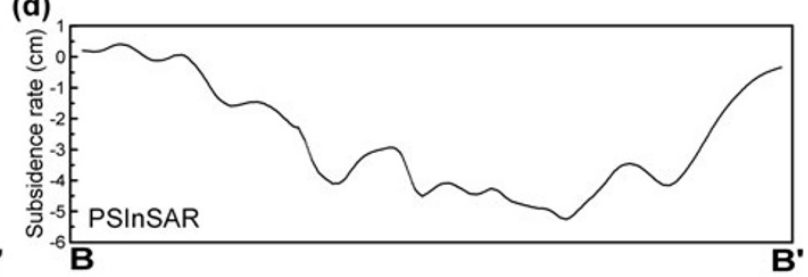

Fig. 4. (a) Subsidence profiles in some typical JERS-1 interferograms along the line A-A' described in Fig. 3(a). Zone 'A1' represents stable area and zones 'A2' and 'A3' represent subsiding area with a different temporal evolution. (b) Subsidence profiles along the line B-B'. (c) and (d) Profiles of the mean subsidence velocity estimated from PSInSAR (see Fig. 6) along the line A-A' and B-B'.

\subsection{Subsidence field from JERS-1 PSInSAR}

The DInSAR analysis allows us not only to detect a deformation field but also to examine a suitable sub-data set for PSInSAR in terms of the continuity of deformation. On the basis of the DInSAR-based subsidence measurements, it appears that the deformation was relatively continuous during the period 1992-1998. In addition, the interferogram between the master image (1996-6-20) and the image acquired before 16 June 1993 reveals a very low coherence around the Hadang areas. This could be explained by temporal decorrelation due to changes made during construction projects, such as readjustments of the land surface and constructions of building. Twenty-two interferograms were used for the PSInSAR analysis, whereas only 18 pairs after June 1993 were used for the Hadang areas.

Figure 5 presents the location and estimated primary velocity of the identified PS ( $\Gamma \geq 0.8$ ) superimposed on the Google Earth image. The most interesting feature is presented in the enlarged window, which shows the area around the Mokpo Stadium. Many PSs appear on the roof and the rightmost side of the right fence; these are favorable to the radar observation direction as double-bounce scatterer, showing the high precision of the geocoding of PS. The accuracy of precise geocoding is crucial for identifying the structures corresponding to each PS (Lanari et al., 2004). Most identified PSs were observed in the urban area because agricultural area and forested mountains are subject to more temporal decorrelation. The density of the final PSs was about $360 / \mathrm{km}^{2}$ which provides sufficient spatial resolution to monitor the ground subsidence patterns that have occurred in the study area.

In order to visually provide a subsidence rate field es-

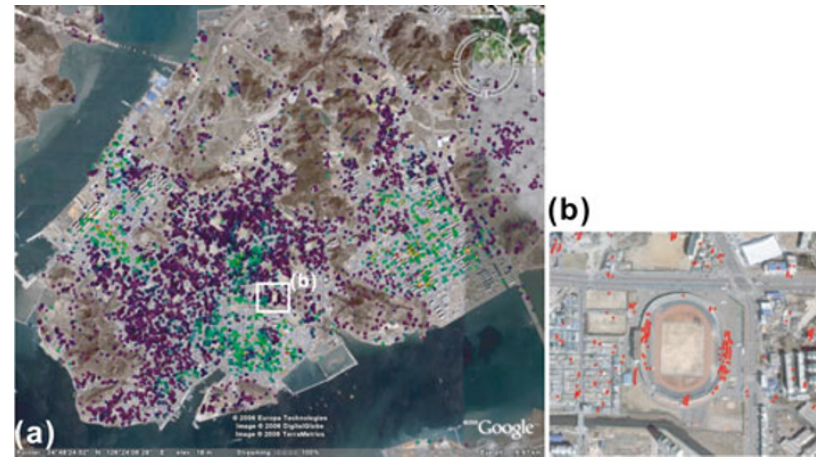

Fig. 5. (a) Location of the identified PSs superimposed on the highresolution optical image of Google Earth; the false color of the circles represents the estimated primary subsidence velocity. (b) The enlarged image shows the distribution of PSs around the Mokpo Stadium wherein the red dot represents the PS location without velocity information.

timated from PSInSAR, we obtained the two-dimensional subsidence velocity over Mokpo City by interpolation and low-pass filtering of the mean subsidence rate measured in correspondence to the PSs (Fig. 6). Figure 6 presents detailed subsidence patterns which provide better results than InSAR measurements in the noisy areas, such as Hadang and Wonsan. Significant subsiding phenomena are closely related to reclaimed coastal areas. The major subsiding areas are confined to the western, southern, and eastern parts of the study area and are in good agreement with DInSAR measurements. Subsidence velocity-after interpolation and low-pass filtering — was compared with subsidence velocity directly estimated from PS analysis, which may provide the variation in the leaking signal by the average 


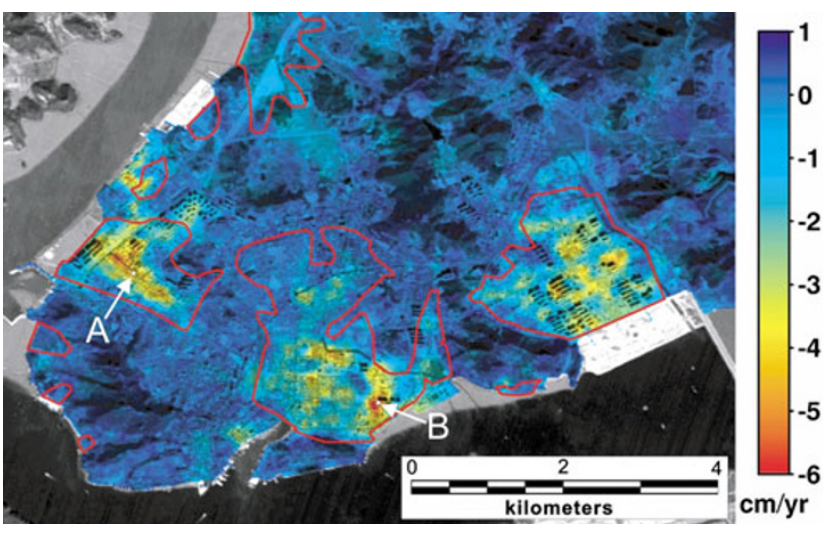

Fig. 6. Subsidence map of Mokpo City derived using the means of the JERS-1 PS analysis. Mean velocities at the PSs were interpolated on a regular spatial grid by means of Kriging interpolation. The background image is the IRS optic image, and the red polygon represents the reclaimed area, as shown in Fig. 1. The temporal evolution of the deformation at two PSs marked by A and B are shown in Fig. 8.

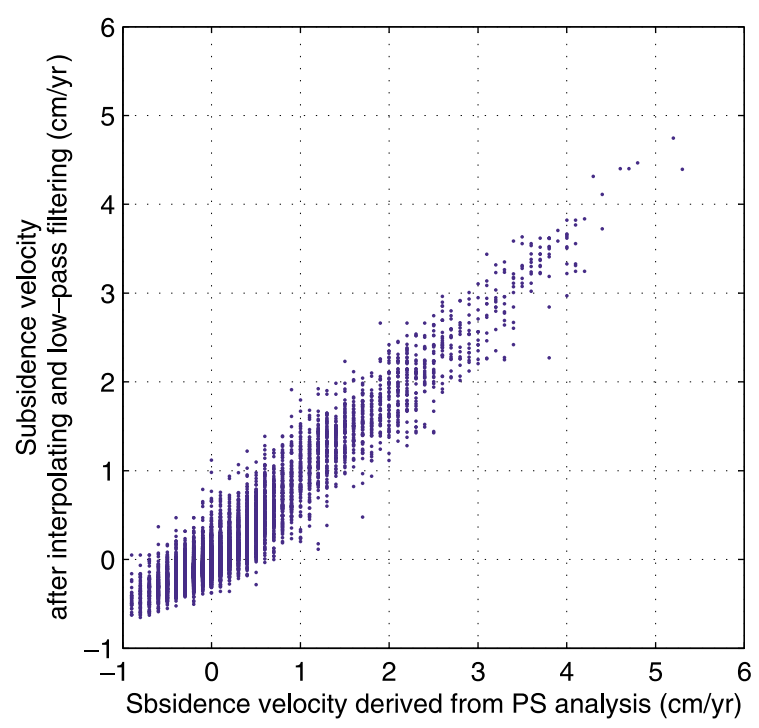

Fig. 7. Scatter plot of subsidence velocity directly estimated from PS analysis and after interplolation and spatial low-pass filtering. The mean and standard deviation of the difference between two velocities is 0.0 and $0.21 \mathrm{~cm} / \mathrm{yr}$.

procedure or some kind of 'internal' accuracy (Fig. 7). The mean and standard deviation estimated from the difference between two velocities is 0.0 and $0.21 \mathrm{~cm} / \mathrm{yr}$, respectively. However, the mean value of the difference at PS with a higher velocity ( $>2 \mathrm{~cm} / \mathrm{yr}$ ) is $0.28 \mathrm{~cm} / \mathrm{yr}$, which could be attributed to a low-pass filtering of a rapid subsiding point different from the neighboring PS.

The statistics of the estimated subsidence rate for the three areas is summarized in Table 1. The estimated averaged subsidence rates are $-1.1,-1.7$, and $-1.6 \mathrm{~cm} / \mathrm{yr}$ in Dongmyung, Wonsan, and Hadang, respectively. The higher rates in Wonsan and Hadang could be explained by the relatively more recent development of the areas. The temporal decorrelation due to recent anthropogenic actions explains the fact that the density of PS observed in Wonsan and Hadang was lower than that observed in Dongmyung. Nevertheless, the observation of 250-900
Table 1. Statistics of PS velocity estimated from the JERS-1 PSInSAR analysis in three major subsidence blocks.

\begin{tabular}{|c|r|r|r|}
\hline \multirow{2}{*}{ Statistic } & \multicolumn{3}{|c|}{ Area } \\
\cline { 2 - 4 } & Dongmyung & \multicolumn{1}{|c|}{ Wonsan } & Hadang \\
\hline Mean & $-1.1 \mathrm{~cm} / \mathrm{yr}$ & $-1.7 \mathrm{~cm} / \mathrm{yr}$ & $-1.6 \mathrm{~cm} / \mathrm{yr}$ \\
\hline Standard deviation & $1.2 \mathrm{~cm} / \mathrm{yr}$ & $1.5 \mathrm{~cm} / \mathrm{yr}$ & $1.2 \mathrm{~cm} / \mathrm{yr}$ \\
\hline Maximum & $-6.6 \mathrm{~cm} / \mathrm{yr}$ & $-5.3 \mathrm{~cm} / \mathrm{yr}$ & $-5.3 \mathrm{~cm} / \mathrm{yr}$ \\
\hline PS density & $907 \mathrm{PS} / \mathrm{km}^{2}$ & $326 \mathrm{PS} / \mathrm{km}^{2}$ & $249 \mathrm{PS} / \mathrm{km}^{2}$ \\
\hline
\end{tabular}
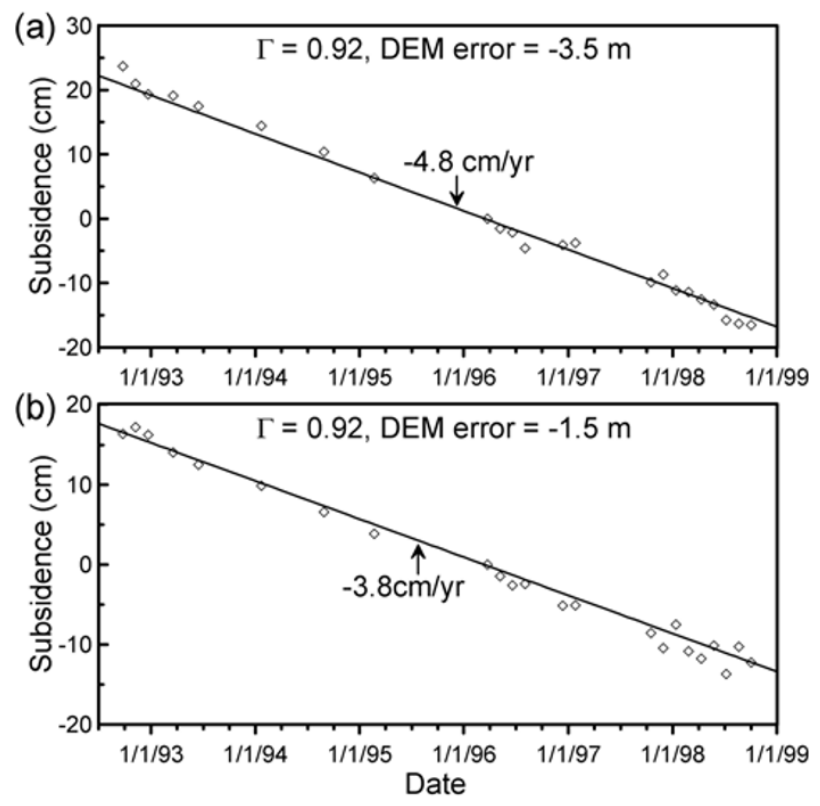

Fig. 8. Time series of elevation change at two selected PS points A (a) and B (b), whose locations are shown in Fig. 6. Estimated mean velocities are $-4.8 \mathrm{~cm} / \mathrm{yr}$ and $-3.8 \mathrm{~cm} / \mathrm{yr}$ in (a) and (b). Temporal coherence and DEM error estimated during PSInSAR processing are presented in the plots.

points per square kilometer cannot be achieved in practice by any other ground measurements, such GPS or leveling. The subsiding area can be clearly identified with respect to the stable area in great spatial detail. For example, the north-south zone, with a width of several kilometers and centering on point $\mathrm{B}$, is the fastest subsiding zone, but the northwestern part immediately adjacent to this zone shows no subsidence. The estimated maximum subsidence rate reached about 5-7 cm/yr in each subsiding zone. All of these three areas are densely populated residential districts in the city of Mokpo. Therefore, this level of subsidence can cause serious damage. In fact, major structural damage to buildings and road subsidence were frequently reported by the local media during the 1990 s and 2000s, especially for the Hadang and Wonsan areas.

PSInSAR provides a deformation component at each SAR acquisition time, so a complete evolution of the deformation can be estimated for each coherent pixel. In order to demonstrate the precise measurement of the deformation, we have selected two PSs in the area showing the most rapid subsidence, which are marked by an A and B in Fig. 6. Figure 8 presents temporal deformation series at two PSs as well as the mean velocity estimated by the PSInSAR analyses. For point $\mathrm{A}$, the mean subsidence rate is -4.8 

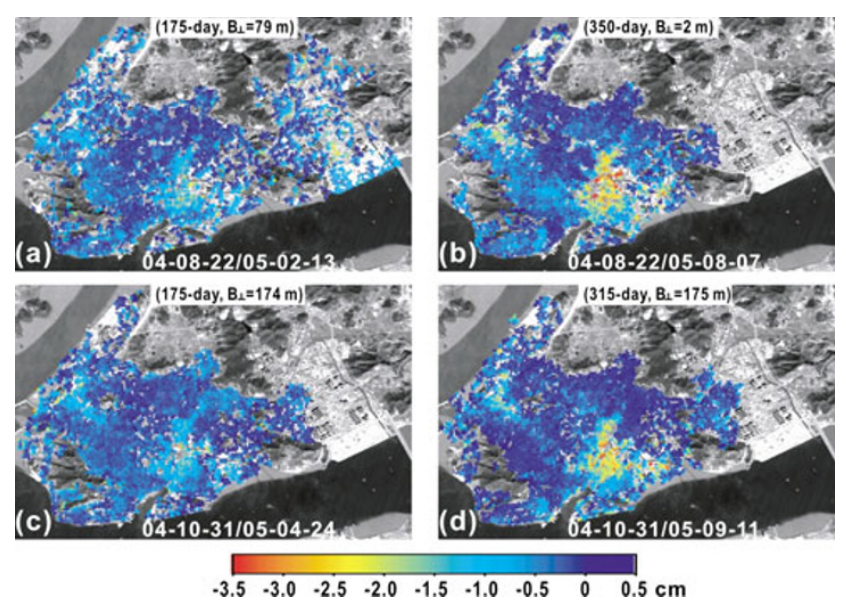

Fig. 9. Deformation maps derived from the ENVISAT ASAR data showing subsidence during the period 2004-2005. Areas of low coherence are uncolored. Subsidence in the eastern area was observed only in (a) because of severe decorrelation and consequent unreliable phase unwrapping in the others.

$\mathrm{cm} / \mathrm{yr}$, and the temporal ensemble coherence and the error of DEM used is 0.92 and $-3.5 \mathrm{~m}$. The mean subsidence rate for point $\mathrm{B}$ is $-3.8 \mathrm{~cm} / \mathrm{yr}$, and the temporal coherence and DEM error are 0.92 and $-1.5 \mathrm{~m}$, respectively. The subsidence rate at each point was estimated by the linear model assuming constant velocity based on the SAR observations, and this observation can be used as the model velocity field in the analysis of forthcoming subsidence.

\subsection{Subsidence field from ENVISAT DInSAR mea- surements}

ENVISAT ASAR images over the study area were acquired on descending orbits and in the time span from 2004 to 2005; no ground measurements are available on the site during the same time period. Using six ENVISAT data sets (see Fig. 2), we selected four DInSAR interferograms showing the highest coherence. The topographic phase component was removed using the SRTM 3-arc DEM and the ENVISAT precise orbit state vectors of technical University of Delft (Doornbos et al., 2002), and the snaphu algorithm was used for phase unwrapping. These subsidence maps allowed us to verify the continuity of the subsidence field derived from the PSInSAR results applied to the JERS-1 data from 1992 to 1998 .

Figure 9 presents subsidence maps calculated from four ENVISAT interferometric pairs. Here, displacements for the radar line-of-sight (LOS) direction of ENVISAT are converted to subsidence values that take into account the incidence angle of $24.8^{\circ}$ under the assumption of pure vertical movements, and low coherence areas have been excluded from the color map. Compared with the JERS-1 L-band pairs shown in Fig. 3, the ENVISAT interferograms show a rather low coherence over all areas due to the high sensitivity of the temporal decorrelation of the C-band. Only the pair of 22 August 2004 and 13 February 2005 shows a meaningful deformation map in the eastern part of the study area. The subsiding zones located in the northern, southern, and eastern parts of the study area are in good agreement with those determined by the JERS- 1 data analysis (Figs. 3 and 6). Subsidence rates of 2-4 and 1-2 cm/yr are observed in Dongmyung and Wonsan, respectively. Note that the subsidence of the northern part of the study area is much lower than that of the south part, while subsidence rates in both areas were almost the same during the period 1992-1998 (see Fig. 6).

\section{Discussion}

The time frame for studying subsidence using SAR data is basically restricted by the passing periods of the satellite. However, assuming that ground subsidence is a longlasting phenomenon, we can use ground subsidence maps obtained from JERS-1 PSInSAR to predict future subsidence. We explored model calculation based on previous PSInSAR results (see Fig. 6) and residuals between the ENVISAT subsidence map and the linear model (i.e., constant velocity). In order to reduce the impacts of temporal decorrelation noise, spatial baseline decorrelation, and possible atmospheric phase delay on each InSAR measurement, we averaged two subsidence maps (Figs. 9(a) and (c)) that have the same time interval of 175 days as well as two other subsidence maps (Figs. 9(b) and 9(d); multiplied by a factor $350 / 315$ before being averaged to take into account the time interval of 315 days) that have the same scaled time interval of 350 days.

Figure 10 shows the linear model subsidence based upon JERS-1 PSInSAR measurements as a function of the time interval of 175 days and 350 days and the residual maps between two averaged ENVISAT subsidence and the models.

The general patterns of model subsidence agree with those of the ENVISAT measurements. A large difference was, however, clearly observed in the residual maps (Figs. 10(b) and 10(d)). The southern area shows both an underestimation (red color) and an overestimation (blue color) in terms of model values, while a large overestimation of the subsidence is evident in the western area. The root mean square (rms) error and mean value of the residuals are summarized in Table 2. The statistics of the residual error of the 175-day measurement was approximately twofold higher than those of the 350-day measurement. Larger residual errors are evident in Wonsan $(0.68 \mathrm{~cm}$ in the 175 -day measurement) and Hadang $(0.67 \mathrm{~cm}$ in the 350 day measurement) located in the northern and eastern areas, respectively. Dongmyung shows a rms of $0.55 \mathrm{~cm}$ for the 175 -day measurement, but it shows a mean error of $0.13 \mathrm{~cm}$, which is in contrast with the large mean errors of 0.32 and 0.38 in Wonsan and Hadang, respectively. The large mean error represents a biased model overall.

The residual map, which basically shows the fitness of the model in terms of subsidence prediction, allows us to easily identify variations in velocity. In terms of subsidence rate, red in a residual map implies a rate increase, blue implies a rate decrease, and green represents no rate changes between the JERS-1 and ENVISAT SAR observations. If the possibility of abrupt velocity change during the time span of the ENVISAT acquisitions is eliminated, this phenomenon may have been caused by the time-varying behavior of the subsidence rate, which was not taken into account in the PSInSAR analysis. In fact, the settlement due to soil consolidation commonly showed a time-waning velocity (Kim and Won, 2003; Tan et al., 1991), depending 

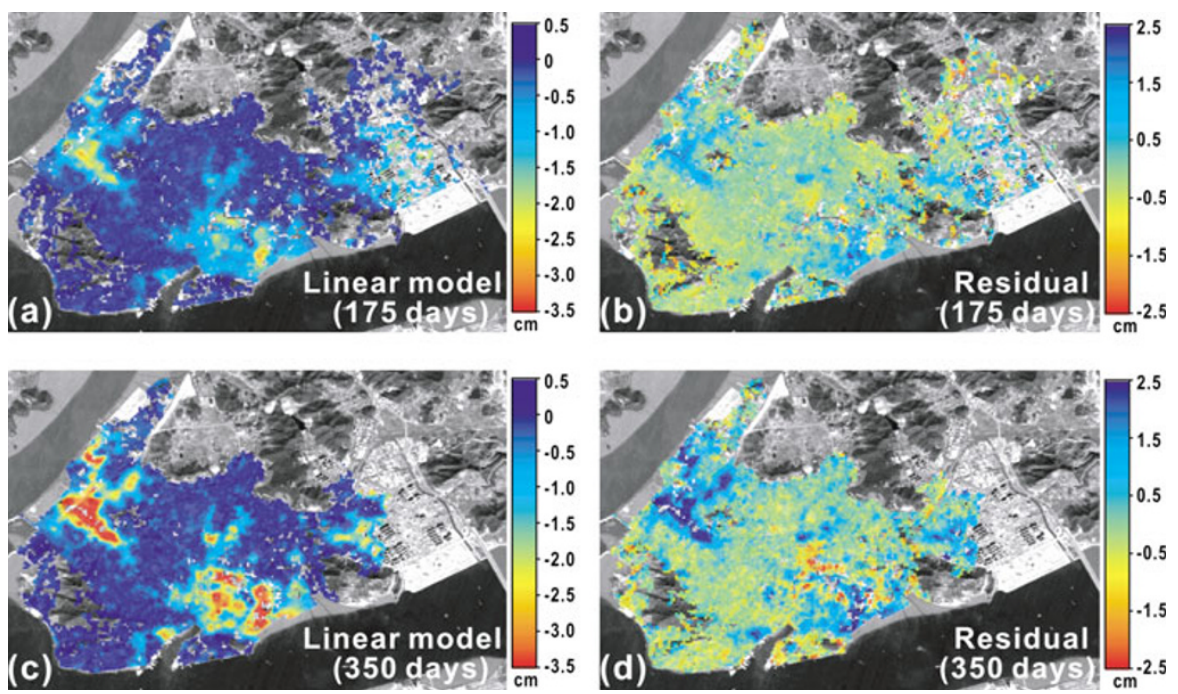

Fig. 10. Subsidence models and residuals for the subsidence during the ENVISAT observation (2004-2005). (a) and (c) Linear model subsidence for 175 and 350 days. (b) The residual map between the 175-day ENVISAT observation (mean of Figs. 8(a) and 8(c)) and the model. (d) The residual map between the 350-day ENVISAT observation (mean of Fig. 8(b) and the scaled Fig. 8(d); see the text) and the model.

Table 2. Residual errors between ENVISAT subsidence maps and subsidence estimations predicted from JERS-1 PSInSAR results.

\begin{tabular}{|c|c|c|c|c|c|}
\hline Time interval & Model & Overall area $(\mathrm{cm})$ & Dongmyung $(\mathrm{cm})$ & Wonsan $(\mathrm{cm})$ & Hadang $(\mathrm{cm})$ \\
\hline \multirow{2}{*}{175 days } & RMSE* & 0.54 & 0.55 & 0.68 & 0.67 \\
\cline { 2 - 7 } & Mean & 0.09 & 0.13 & 0.32 & 0.38 \\
\hline \multirow{2}{*}{350 days } & RMSE & 0.93 & 0.91 & 1.45 & - \\
\cline { 2 - 7 } & Mean & 0.29 & 0.20 & 0.97 & - \\
\hline
\end{tabular}

*Root mean square error.

on a different soil texture of underlying sediments and a different stage of subsidence development. Therefore, the decrease in velocity can be a reasonable develpment in the study area and, consequently, the linear model used for the PSInSAR analysis may not be good enough to account for the subsidence in this area. Although it is essential to acquire data on the entire subsiding area detected by the study, the zone showing constant or increasing velocity should be investigated more thoroughly in terms of a potential hazard risk.

\section{Conclusion}

The SAR interferometric analysis revealed that the Mokpo City area has experienced serious subsidence. This subsidence is considered to be mostly the result of soil consolidation related to reclamation and construction activities because subsiding areas are in good agreement with lands reclaimed from tidal flats or areas of shallow water. The subsidence map derived from JERS-1 L-band SAR data between September 1992 and October 1998 reveals the spatial extent of the deformations and subsidence velocity. The results from both DInSAR and PSInSAR indicate continuous subsidence in the western, southern and eastern parts of the city and that the maximum subsidence rate reaches over $5-6 \mathrm{~cm} / \mathrm{yr}$ in the fastest subsiding areas in three main subsiding zones.

In terms of risk assessment, both the detection of subsidence during the SAR observations and the possibility of prediction are important factors to be considered. The val- idation of the subsidence field measured from the JERS-1 data (1992-1998) was carried out by comparing the subsidence maps estimated from the ENVISAT ASAR data during the period 2004-2005. According to our results, subsidence has occurred continuously in the same zone, as detected from JERS-1 during the ENVISAT observation. The residuals between the linear model estimation and the ENVISAT measurement over a 175-day and 350-day period are 0.5 and $0.9 \mathrm{~cm}$ as the rms error, and 0.1 and $0.3 \mathrm{~cm}$ as the mean, respectively. Based on the temporal change of rate as well as the rate of subsidence, we consider that the central part of the study area has the highest potential risk because the subsidence rate there $(\sim 3 \mathrm{~cm} / \mathrm{yr})$ did not decrease during the period 1992-2005.

Based on our observations, continuous monitoring is required to prevent severe structural damage to the city in the future. Our results can be used to define the risk zones for future ground settlement and to establish a ground survey plan with information on rapidly subsiding areas and detailed time-series deformation at each PS. Our results clearly confirm that SAR interferometry is a valuable tool for monitoring long-term land subsidence.

Acknowledgments. We thank NASA and ONR for support. The research was supported by the National Research Lab. Project (M1-0302-00-0063) of the Korea Ministry of Science and Technology. CSTARS publications \# 8.

\section{References}

Amelung, F., D. L. Galloway, J. W. Bell, H. A. Zebker, and R. J. Laczniak, 
Sensing the ups and downs of Las Vegas: InSAR reveals structural control of land subsidence and aquifer-system deformation, Geology, 27, 483-486, 1999

Burgmann, R., P. A. Rosen, and E. J. Fielding, Synthetic aperture radar interferometry to measure Earth's surface topography and its deformation, Ann. Rev. Earth Planet. Sci., 28, 169-209, 2000.

Chen, C. W. and H. A. Zebker, Two-dimensional phase unwrapping with use of statistical models for cost functions in nonlinear optimization, $J$. Optical Soc. Am. a-Optics Image Sci. Vision, 18, 338-351, 2001.

Colesanti, C., A. Ferretti, F. Novali, C. Prati, and F. Rocca, SAR monitoring of progressive and seasonal ground deformation using the permanent scatterers technique, IEEE Trans. Geosci. Remote Sensing, 41, 1685-1701, 2003.

Daito, K., A. Ferretti, S. Kuzuoka, F. Novali, P. Panzeri, and F. Rocca, Lband PS analysis: JERS-1 results and TerraSAR-L predictions, in Fringe 2003 Wrokshop, ESRIN, Frascati, Italy, 2003.

Dixon, T. H., F. Amelung, A. Ferretti, F. Novali, F. Rocca, R. Dokka, G. Sella, S. W. Kim, S. Wdowinski, and D. Whitman, Subsidence and flooding in New Orleans, Nature, 441, 587-588, 2006.

Doornbos, E., R. Scharroo, H. Klinkrad, R. Zandbergen, and B. Fritsche, Improved modelling of surface forces in the orbit determination of ERS and ENVISAT, Can. J. Remote Sensing, 28, 535-543, 2002.

Ferretti, A., C. Prati, and F. Rocca, Nonlinear subsidence rate estimation using permanent scatterers in differential SAR interferometry, IEEE Trans. Geosci. Remote Sensing, 38, 2202-2212, 2000.

Ferretti, A., C. Prati, and F. Rocca, Permanent scatterers in SAR interferometry, IEEE Trans. Geosci. Remote Sensing, 39, 8-20, 2001.

Fruneau, B. and F. Sarti, Detection of ground subsidence in the city of Paris using radar interferometry: isolation of deformation from atmospheric artifacts using correlation, Geophys. Res. Lett., 27, 3981-3984, 2000.

Galloway, D. L., D. R. Jones, and S. E. Ingebritsen, Land subsidence in the United States, In. Denver: USGS, 1999.

Hilley, G. E., R. Burgmann, A. Ferretti, F. Novali, and F. Rocca, Dynamics of slow-moving landslides from permanent scatterer analysis, Science, 304, 1952-1955, 2004.

Hu, R. L., Z. Q. Yue, L. C. Wang, and S. J. Wang, Review on current status and challenging issues of land subsidence in China, Eng. Geol., 76, 65$77,2004$.
Kim, S. W. and J. S. Won, Measurements of soil compaction rate by using JERS-1 SAR and a prediction model, IEEE Trans. Geosci. Remote Sensing, 41, 2683-2686, 2003.

Kim, S. W., C. O. Kim, J. S. Won, and J. W. Kim, Measurement of Ground Subsidence in Mokpo Area from Radar Intrerferometry (Korean Ed.), Econ. Environ. Geol., 38, 381-394, 2005a.

Kim, S. W., C. W. Lee, K. Y. Song, K. D. Min, and J. S. Won, Application of L-band differential SAR interferometry to subsidence rate estimation in reclaimed coastal land, Int. J. Remote Sensing, 26, 1363-1381, 2005b.

Lanari, R., O. Mora, M. Manunta, J. J. Mallorqui, P. Berardino, and E. Sansosti, A small-baseline approach for investigating deformations on full-resolution differential SAR interferograms, IEEE Trans. Geosci. Remote Sensing, 42, 1377-1386, 2004.

Massonnet, D. and K. L. Feigl, Radar interferometry and its application to changes in the earth's surface, Rev. Geophys., 36, 441-500, 1998.

Massonnet, D., M. Rossi, C. Carmona, F. Adragna, G. Peltzer, K. Feigl, and T. Rabaute, The Displacement Field Of The Landers Earthquake Mapped By Radar Interferometry, Nature, 364, 138-142, 1993.

Muller, J.-P. and D. Backes, Quality assessment of X- and C-SRTM with ERS-tandem DEMs over 4 European CEOS WGCV test sites, in Fringe 2003 Workshop, Frascati, Italy, 2003.

Strozzi, T., U. Wegmuller, C. L. Werner, A. Wiesmann, and V. Spreckels, JERS SAR interferometry for land subsidence monitoring, IEEE Trans. Geosci. Remote Sensing, 41, 1702-1708, 2003.

Tan, T. S., T. Inoue, and S. L. Lee, Hyperbolic Method for Consolidation Analysis, J. Geotechn. Eng.-Asce, 117, 1723-1737, 1991.

Teatini, P., L. Tosi, T. Strozzi, L. Carbognin, U. Wegmuller, and F. Rizzetto, Mapping regional land displacements in the Venice coastland by an integrated monitoring system, Remote Sensing Environ., 98, 403-413, 2005.

Zebker, H. A., P. A. Rosen, R. M. Goldstein, A. Gabriel, and C. L. Werner, On the Derivation of Coseismic Displacement-Fields Using Differential Radar Interferometry - the Landers Earthquake, J. Geophys. Res.-Solid Earth, 99, 19617-19634, 1994.

S.-W. Kim, S. Wdowinski, T. H. Dixon, F. Amelung, J.-S. Won, and J. W. Kim (e-mail: jw.kim@ucalgary.ca) 